\title{
Golden Tracheal Secretions and Bronchoalveolar Fluid During Acute Chest Syndrome in Sickle Cell Disease
}

\author{
Damien Contou MD, Armand Mekontso Dessap MD PhD, \\ Guillaume Carteaux MD, Christian Brun-Buisson MD, \\ Bernard Maitre MD PhD, and Nicolas de Prost MD PhD
}

\begin{abstract}
Acute chest syndrome (ACS) is the leading cause of ICU admission in patients with sickle cell disease and is characterized by golden sputum, which is commonly attributed to the presence of bilirubin. Three young consecutive patients with homozygous sickle cell disease were admitted for severe acute respiratory syndrome due to ACS. In all 3 patients, tracheal secretions and bronchoalveolar lavage fluid (BALF) showed a yellowish plasma-like stain. After normalization for the plasma-to-BAL urea ratio, BALF protein and lactate dehydrogenase levels were consistent with an exudative process. BALF bilirubin concentrations were very low, implying that the yellowish stain was not related to bilirubin content. The yellowish coloration of tracheal secretions and BALF observed during ACS appears to be related to an intense exudative process rather than to the presence of bilirubin. Key words: sickle cell disease; acute chest syndrome; yellow sputum; acute respiratory distress syndrome; pulmonary fat embolism; intensive care. [Respir Care 2015;60(4):e73-e75. (C) 2015 Daedalus Enterprises]
\end{abstract}

\section{Introduction}

Acute chest syndrome (ACS) is the leading cause of ICU admission in patients with sickle cell disease. ${ }^{1}$ The main complication of ACS is severe acute respiratory syndrome, which can lead to refractory hypoxemia and death. Golden sputum is a hallmark of ACS and is commonly attributed to the presence of bilirubin, also termed bilioptysis, ${ }^{2}$ even though this term initially referred to the existence of a bronchobiliary fistula.

\footnotetext{
The authors are affiliated with the Service de Réanimation Médicale, Cardiovascular and Respiratory Manifestations of Acute Lung Injury and Sepsis (CARMAS) Research Group, Groupe Henri Mondor-Albert Chenevier, Assistance Publique Hôpitaux de Paris and Université Paris-Est Créteil Val de Marne, Créteil, France. Drs Contou, Dessap, and de Prost are also affiliated with the Institut National de la Santé et de la Recherche Médicale, Unité U955, Créteil, France. Dr Maitre is also affiliated with the Antenne de Pneumologie, Service de Réanimation Médicale, Groupe Henri Mondor-Albert Chenevier, Assistance Publique Hôpitaux de Paris, Créteil, France.

Supplementary material related to this paper is available at http:// www.rcjournal.com.
}

\section{Case Reports}

Three young female patients with known homozygous sickle cell disease were admitted to our ICU over a 1-week period for acute respiratory failure due to ACS following painful vaso-occlusive crises. The baseline characteristics of sickle cell disease, clinical and laboratory features upon ICU admission, and outcomes of these 3 patients are reported in Table 1. All 3 developed severe acute respiratory syndrome, leading to tracheal intubation, prone positioning, and nitric oxide inhalation treatment. Intravenous antibiotic treatment, combining a third-generation cephalosporin and a macrolide, was administered to all 3 patients, but bacterial blood cultures and respiratory samples re-

\footnotetext{
The authors have disclosed no conflicts of interest.

Correspondence: Nicolas de Prost MD PhD, Service de Réanimation Médicale, Groupe Henri Mondor-Albert Chenevier, Assistance Publique Hôpitaux de Paris, 51 avenue du Maréchal de Lattre de Tassigny, 94010 Créteil Cedex, France. E-mail: nicolas.de-prost@hmn.aphp.fr.
}

DOI: $10.4187 /$ respcare.03517 
Golden Tracheal Secretions and BAlf During ACS in Sickle Cell Disease

Table 1. Presentation and Outcomes of Patients With Severe Acute Chest Syndrome

\begin{tabular}{|c|c|c|c|}
\hline & Patient 1 & Patient 2 & Patient 3 \\
\hline Age, y & 21 & 21 & 34 \\
\hline \multicolumn{4}{|l|}{ Baseline characteristics of sickle cell disease } \\
\hline Type of hemoglobinopathy & SS & SS & SS \\
\hline Baseline hemoglobin, g/L & 76 & 80 & 50 \\
\hline History of ACS in the preceding year & No & Yes & No \\
\hline Blood transfusion program & No & No & Yes \\
\hline Hydroxycarbamide treatment & Yes & Yes & Yes \\
\hline \multicolumn{4}{|l|}{ Features upon ICU admission } \\
\hline Hemoglobin, g/L & 75 & 87 & 35 \\
\hline Lactate dehydrogenase, U/L & 733 & 364 & 1920 \\
\hline Total bilirubin, $\mu \mathrm{mol} / \mathrm{L}$ & 65 & 88 & 200 \\
\hline Platelets, $6 \times 10^{3}$ cells $/ \mu \mathrm{L}$ & 283 & 257 & 238 \\
\hline Prothrombin time, $\%$ & 65 & 58 & 48 \\
\hline Serum creatinine, $\mu \mathrm{mol} / \mathrm{L}$ & 27 & 45 & 352 \\
\hline Chest CT scan & $\begin{array}{l}\text { Bilateral lung base consolidations } \\
\text { without pulmonary thrombosis }\end{array}$ & Not performed & $\begin{array}{l}\text { Bilateral lung base consolidations } \\
\text { without pulmonary thrombosis }\end{array}$ \\
\hline \multicolumn{4}{|l|}{ Echocardiography } \\
\hline Acute cor pulmonale & Yes & Yes & Yes \\
\hline Pulmonary artery systolic pressure, $\mathrm{mm} \mathrm{Hg}$ & 60 & 80 & 80 \\
\hline \multicolumn{4}{|l|}{ Outcomes in ICU } \\
\hline Orotracheal intubation & Yes (day 2) & Yes (day 1) & Yes (day 1) \\
\hline $\begin{array}{l}\text { Minimal } \mathrm{P}_{\mathrm{aO}_{2}} / \mathrm{F}_{\mathrm{IO}_{2}} \text { before prone positioning, } \\
\mathrm{mm} \mathrm{Hg}\end{array}$ & 74 & 73 & 115 \\
\hline Prone positioning & Yes (day 2) & Yes (day 1) & Yes (day 2) \\
\hline Nitric oxide inhalation & Yes (day 2) & Yes (day 1) & Yes (day 1) \\
\hline Venovenous ECMO & No & Yes (day 1) & No \\
\hline Total number of transfused RBC units & 5 & 10 & 7 \\
\hline Vasoactive drugs & No & Yes & Yes \\
\hline Renal replacement therapy & No & Yes & Yes \\
\hline ICU stay, d & 9 & 5 & 10 \\
\hline Death & No & Yes & No \\
\hline SAPS II score & 29 & 61 & 75 \\
\hline $\begin{array}{l}\text { ACS }=\text { acute chest syndrome } \\
\text { CT }=\text { computed tomography } \\
\text { ECMO = extracorporeal membrane oxygenation } \\
\text { RBC }=\text { red blood cell } \\
\text { SAPS II = Simplified Acute Physiology Score II. }\end{array}$ & & & \\
\hline
\end{tabular}

mained sterile. The condition improved in 2 patients, who were eventually discharged from the ICU 2 weeks later (patients 1 and 3), whereas one patient (patient 2) required venovenous extracorporeal membrane oxygenation and died on day 5.

In all 3 patients, tracheal secretions and bronchoalveolar lavage fluid (BALF) showed a yellowish plasma-like stain (Fig. 1, B-D; see the supplementary video at http://www. rcjournal.com). After normalization for the plasma-to-BAL urea ratio, BALF (vs plasma) protein (patient 1, 54 vs $57 \mathrm{~g} / \mathrm{L}$; patient $2,45 \mathrm{vs} 55 \mathrm{~g} / \mathrm{L}$ ) and lactate dehydrogenase (patient $1,1,890$ vs $1,529 \mathrm{U} / \mathrm{L}$; patient 2,795 vs $512 \mathrm{U} / \mathrm{L}$ ) levels were similar and consistent with an exudative process. BALF bilirubin concentrations were 7 (patient 1) and
5 (patient 2) $\mu \mathrm{mol} / \mathrm{L}$, implying that the yellowish stain was not related to bilirubin content. Interestingly, tracheal secretions of patient 3 exhibited the same color as her plasma (Fig. 1C). Finally, in patients 1 and 2, 30\% of alveolar macrophages were stained with Oil Red O (Fig. 1E), indicative of lung fat embolism. ${ }^{3-5}$

\section{Discussion}

Golden sputum is a classic and pathognomonic sign of ACS, which is often associated with pulmonary fat embolism. ${ }^{3-5}$ This yellowish coloration appears to be related to an intense exudative process rather than to the presence of bilirubin. Of course, this finding has limited 


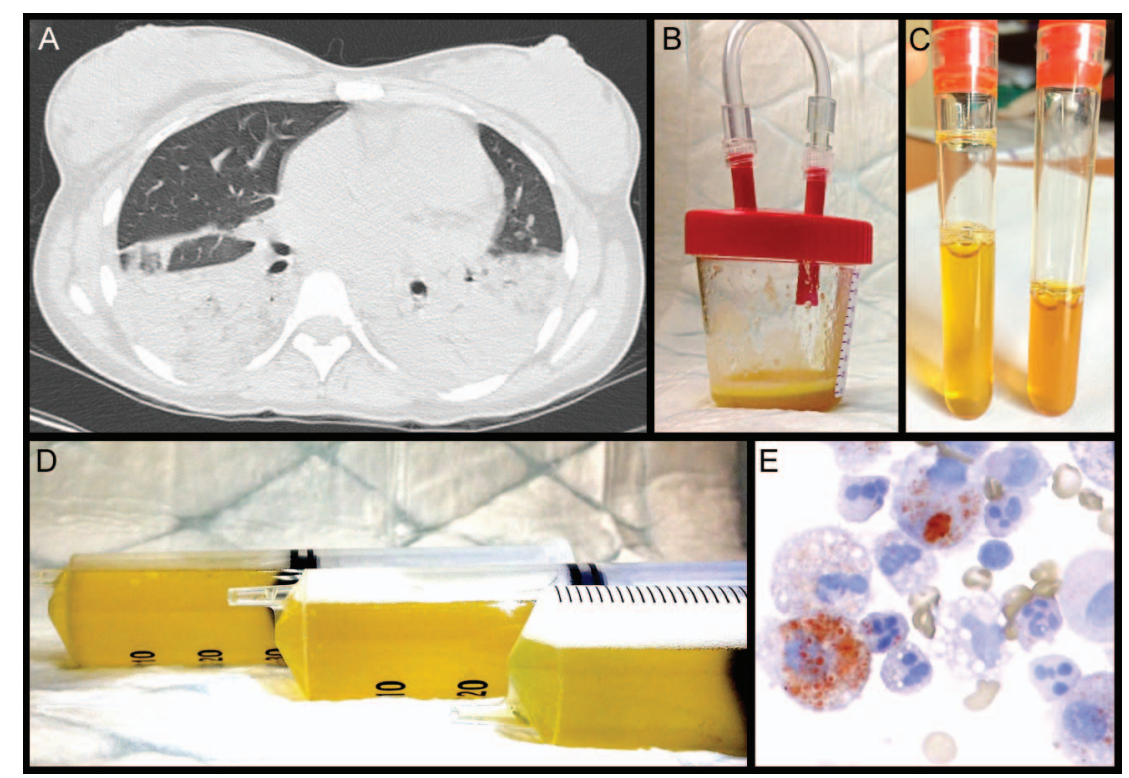

Figure 1. Golden tracheal aspirates and bronchoalveolar lavage fluid (BALF) in patients with severe acute chest syndrome. A: Contrastenhanced chest computed tomography scan depicting typical bilateral lung base consolidations in patient 1. B: Tracheal secretions from patient 1. C: Tracheal secretions (left tube) and plasma (right tube) from patient 3 showing the same yellowish color. D: Macroscopically golden BALF from patient 1. E: Cytological examination of BALF from patient 1 showing alveolar macrophages stained with Oil Red O.

clinical implications for the current management of patients with ACS. However, understanding the pathophysiologic phenomena underlying this yellowish stain, which is not commonly reported during ARDS in patients without sickle cell disease, could be of paramount importance for the management of ACS. Future studies aiming at determining the components of this peculiar alveolar fluid (eg, using proteomics) could allow for the identification of specific diagnostic or therapeutic markers of ACS.

\section{ACKNOWLEDGMENT}

We thank Dr Jeanne Tran Van Nhieu for providing images of macrophages stained with Oil Red O.

\section{REFERENCES}

1. Cecchini J, Lionnet F, Djibré M, Parrot A, Stojanovic KS, Girot R, Fartoukh M. Outcomes of adult patients with sickle-cell disease admitted to the ICU: a case series. Crit Care Med 2014;42(7):16291639.

2. Brandstetter RD, Kabinoff GS. Bilioptysis: a sign of pulmonary capillary permeability injury. Heart Lung 1998;27(2):121-122.

3. Godeau B, Schaeffer A, Bachir D, Fleury-Feith J, Galacteros F, Verra F, et al. Bronchoalveolar lavage in adult sickle cell patients with acute chest syndrome: value for diagnostic assessment of fat embolism. Am J Respir Crit Care Med 1996;153(5):1691-1696.

4. Lechapt E, Habibi A, Bachir D, Galacteros F, Schaeffer A, Desvaux $\mathrm{D}$, et al. Induced sputum versus bronchoalveolar lavage during acute chest syndrome in sickle cell disease. Am J Respir Crit Care Med 2003;168(11):1373-1377.

5. Maitre B, Habibi A, Roudot-Thoraval F, Bachir D, Belghiti DD, Galacteros F, Godeau B. Acute chest syndrome in adults with sickle cell disease. Chest 2000;117(5):1386-1392. 